\title{
From the Case Records of Kanchi Kamakoti CHILDS Trust Hospital: An Adolescent with Recurrent Meningitis
}

\author{
Sundaram Balasubramanian ${ }^{1}$, Kuppusamy Dhanalakshmi $^{2}$, Silky Agarwal ${ }^{3}$, Sabapathyraj L Raj ${ }^{4}$
}

Pediatric Infectious Disease (2019): 10.5005/jp-journals-10081-1222

\section{Dr Lakshan Raj}

Sir today, we would like to discuss with you a case of an adolescent who has been referred with a suspected diagnosis of recurrent meningitis.

An 11-year-old boy has been presented with fever, headache, and vomiting for 3 days with a probable diagnosis of meningitis. I took a detailed history from the parents which revealed the following. He was having fever more than $102^{\circ} \mathrm{F}$ most of the time in the last 3 days. Headache was severely associated with vomiting and disturbed sleep. He was admitted elsewhere and was given meropenem and vancomycin with paracetamol IV. The pediatrician has referred him to our hospital with a diagnosis of meningitis. On examination, he had terminal nuchal rigidity which was suggestive of meningitis. Rest of the examination including fundus examination did not reveal findings except a temperature of $102^{\circ} \mathrm{F}$. I have ordered for complete blood count (CBC), renal function tests (RFT), liver function tests (LFT) and have planned a lumbar puncture and cerebrospinal fluid (CSF) analysis (Fig. 1).

I took a detailed history from the parents which revealed that he had a similar episode 8 months back. He had fever, headache, and vomiting for 3 days and was treated outside. The CSF analysis done at that time was suggestive of aseptic meningitis [cells-400 ( $\mathrm{N}-30$ and $\mathrm{L}-70$ ) and CSF protein-3.16 $\mathrm{mg} / \mathrm{dL}$ and CSF sugar$14 \mathrm{mg} / \mathrm{dL}$. The CSF culture was negative (Fig. 2). Magnetic resonance imaging (MRI) during that episode was reported to show thickened meninges. He was treated with 14 days of IV parenteral antibiotics (meropenem + amikacin) and recovered completely. Child was well for 8 months. For the present episode of illness, he received antibiotics (meropenem + vancomycin + dexamethasone).

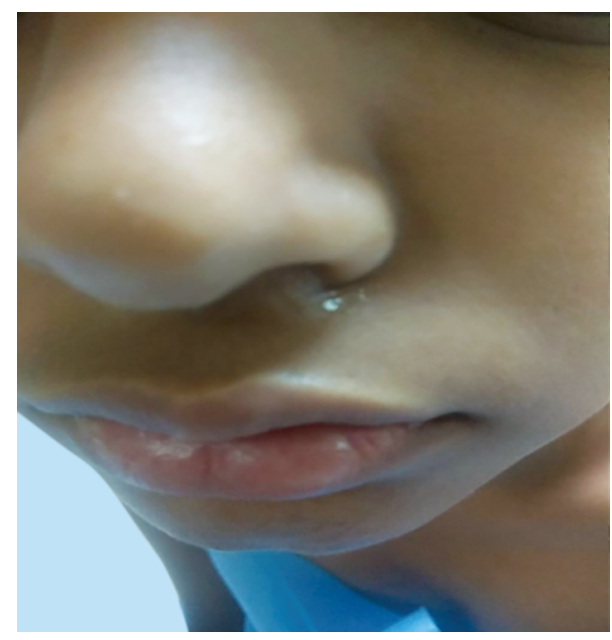

Fig. 1: CSF leak from the left nostril after intrathecal administration of fluorescein dye

\author{
${ }^{1-4}$ Department of Pediatrics, Kanchi Kamakoti CHILDS Trust Hospital, \\ Chennai, Tamil Nadu, India
}

Corresponding Author: Sundaram Balasubramanian, Department of Pediatrics, Kanchi Kamakoti CHILDS Trust Hospital, Chennai, Tamil Nadu, India, Phone: +91 9840218954, e-mail: sbsped@gmail.com

How to cite this article: Balasubramanian S, Dhanalakshmi K, Agarwal S, et al. From the Case Records of Kanchi Kamakoti CHILDS Trust Hospital: An Adolescent with Recurrent Meningitis. Pediatr Inf Dis 2019;1(3): 131-133.

Source of support: Nil

Conflict of interest: None

It looks like this boy is having recurrent meningitis. He has had two episodes of meningitis with an asymptomatic interval of 8 months. Meanwhile, Dr Silky has referred to literature and wants to discuss the etiology of recurrent meningitis (Flowchart 1).

Dr Silky:

Recurrent meningitis is defined as two or more episodes of meningitis due to different bacterial organism or a second or further episode caused by the same organism with a greater-than-3-week interval after the completion of therapy for the initial episode. It is also defined as two or more episodes of meningitis defined by abnormal CSF results if the episodes occurred a minimum of 3 weeks apart. ${ }^{1,2}$

Three most common groups have been reported to cause recurrent meningitis: (1) anatomical defects, (2) immunodeficiencies, and (3) chronic infections (mastoiditis, otitis media, etc.).

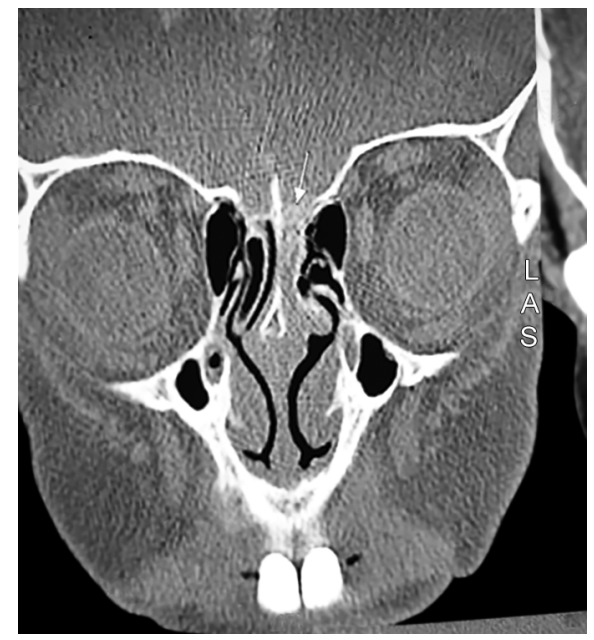

Fig. 2: Cribriform plate defect identified in CT cisternogram

(c) The Author(s). 2019 Open Access This article is distributed under the terms of the Creative Commons Attribution 4.0 International License (https://creativecommons. org/licenses/by-nc/4.0/), which permits unrestricted use, distribution, and non-commercial reproduction in any medium, provided you give appropriate credit to the original author(s) and the source, provide a link to the Creative Commons license, and indicate if changes were made. The Creative Commons Public Domain Dedication waiver (http://creativecommons.org/publicdomain/zero/1.0/) applies to the data made available in this article, unless otherwise stated. 
Flowchart 1: Algorithm for evaluation of recurrent meningitis
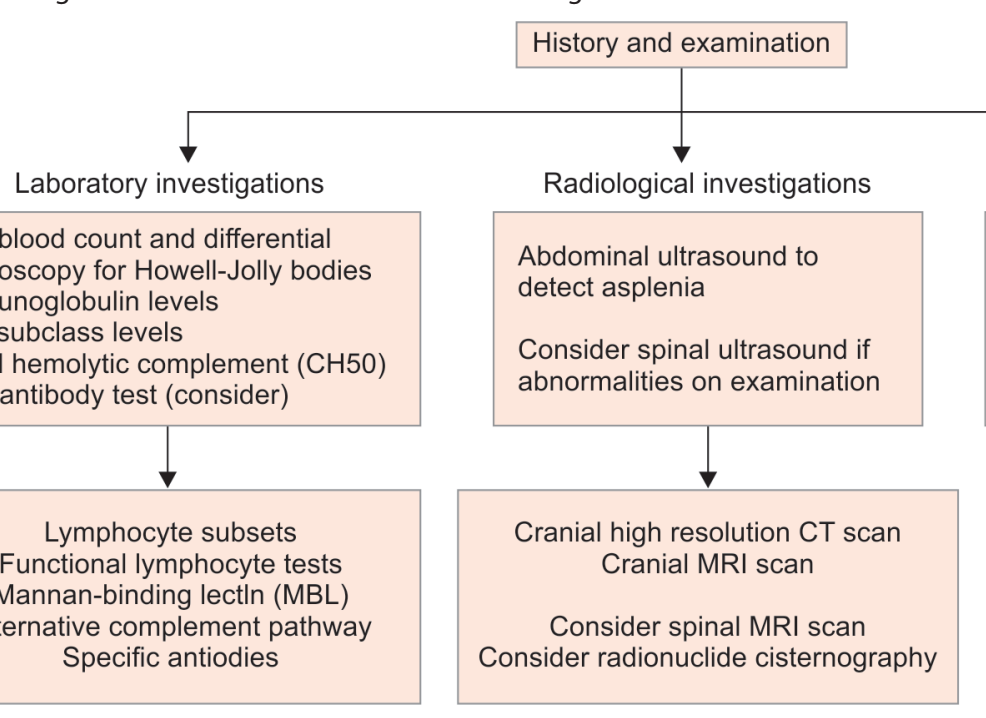

Other investigations

Audiological assessment
$\begin{gathered}\text { Assessment by } \\ \text { otorhinolaryngologist }\end{gathered}$
$\begin{gathered}\text { At any point: } \\ \text { I undertake directed } \\ \text { investigations } \\ \text { if abnormality detected }\end{gathered}$

First line investigations

Second line investigations

Table 1: Causes of recurrent meningitis in pediatric age group

\begin{tabular}{lll}
\hline Anatomical problems & Immunodeficiencies & Chronic infections \\
\hline Cranial and cervical anatomical defects & HIV infection & $\begin{array}{l}\text { Parameningeal infections } \\
\text { Chronic otitis media/mastoiditis } \\
\text { Chronic sinusitis }\end{array}$ \\
$\begin{array}{l}\text { Heterotopic brain tissue (congenital) } \\
\text { (meningocele/meningoencephalocele) }\end{array}$ & Complement deficiencies & \\
$\begin{array}{l}\text { Skull base defects (likely congenital) } \\
\text { Dermoid cyst/epidermoid cyst/dermal } \\
\text { sinus tract }\end{array}$ & Agammaglobulinemia \\
$\begin{array}{l}\text { Neurenteric cyst } \\
\text { Inner ear abnormality (unspecified) }\end{array}$ & IRAK-4 deficiency \\
$\begin{array}{l}\text { Mondini dysplasia } \\
\text { Head injury/basal skull fractures }\end{array}$ & Asplenism (iatrogenic and congenital) \\
Lumbosacral anatomical defects & & \\
Dermal sinus/dermoid cyst & & \\
Meningocele & & \\
\hline
\end{tabular}

The predisposing factors for recurrent bacterial meningitis can be broadly categorized into congenital and acquired conditions and further divided into anatomical abnormalities, immunodeficiencies, and chronic parameningeal infections (Table 1). ${ }^{1,3}$ Streptococcus pneumoniae is the most common causative agent in recurrent bacterial meningitis after head trauma, followed by Haemophilus influenzae and Neisseria meningitidis. ${ }^{1}$

As many as $6 \%$ of patients presenting with community-acquired meningitis develop a subsequent recurrence. ${ }^{4}$

In cases related to anatomical problems, the abnormality is more often identified in the cranial or cervical region than in the lumbosacral location. The largest group in this category is due to traumatic head injury with secondary CSF fistula.

Complement deficiency, human immunodeficiency virus (HIV) infection, agammaglobulinemia, immunoglobulin G (lgG) subclass deficiency, common variable immunodeficiency, interleukin-1 receptor-associated kinase 4 (IRAK-4) deficiency, and asplenia are the ones frequently reported in association with recurrent meningitis with complement deficiency being the most common one.
Interestingly, less mortality has been reported in recurrent meningitis when compared with the first episodes, and this is attributed to caretakers' increased awareness due to past experience. 4

Dr Dhanalakshmi K:

Anatomic abnormalities, including defects of the cribriform plate, may be less common than immunologic defects in children. Is there a reference?

In the pediatric population, recurrent meningitis frequently warrants an immunology workup. However, on revisiting the history, the parents informed that this boy had been having watery discharge from left nostril intermittently whenever he bent forward for over a year. There was no history of any trauma prior to this. With background history of meningitis, could this be some congenital skull defect causing spontaneous CSF rhinorrhea.

Dr SBS:

Compliments for obtaining this crucial information in history. This is very much suggestive of CSF rhinorrhea. The true percentage of pediatric patients with basilar skull fracture or CSF leak who 
develop meningitis is unclear. In children, the most common cause of CSF rhinorrhea is a defect in the cribriform plate. CSF rhinorrhea can be congenital or acquired. It can be acquired by trauma, tumor, or spontaneously. Spontaneous fistula can be further subdivided as primary cases, where no underlying cause can be found, or they can be secondary to intracranial pathology (normal or high intracranial pressure). In over $80 \%$ of traumatic cases, head injury resulting in skull base fracture is implicated as the common cause. ${ }^{5}$

History given by the patient and the analysis of the nasal fluid are the initial diagnostic tools to suspect CSF rhinorrhea, specifically the history of recurrent meningitis. The commonest cause for CSF rhinorrhea is head injury though in this boy there had been no history for that. Interestingly, post-head injury CSF leaks have been delayed in many instances as long as 34 years. ${ }^{6}$

Let us proceed further to find out methods for investigating CSF rhinorrhea.

\section{Dr Dhanalakshmi}

Radiological investigations like contrast-enhanced computed tomography (CT) and MRI scan help in confirming the diagnosis and in localizing the site of the defect. Computed tomography cisternography ${ }^{7}$ is the gold standard for diagnosis of CSF rhinorrhea. Intrathecal sodium fluorescein can also be used to localize the site of the defect intraoperatively. $\beta 2$ Transferrin detection in the nasal fluid is diagnostic for $\mathrm{CSF}^{8,9}$ not easily performed due to the lack of facility for the same. We will do a CT scan, as these defects can be caused by trauma (either accidental or iatrogenic), congenital defects, tumors, or meningoencephaloceles.

Dr Silky:

The preliminary investigations are now available sir. CBC, RFT, and LFT are normal. We proceeded with the CSF analysis which revealed the following: cells -12 with $\mathrm{N}-8$ and total leucocyte count (TLC) of 92 and protein-21 mg/dL and sugars - $58 \mathrm{mg} / \mathrm{dL}$. No organisms were identified in Gram's stain or culture. As planned, the CT cisternogram was done which showed that there was a CSF leak from left nostril after intrathecal administration of fluorescein dye. CT imaging was suggestive of left cribriform plate defect. Now with the diagnosis of CSF rhinorrhea confirmed what next? (Figs 1 and 2).

\section{Dr Dhanalakshmi K:}

CSF rhinorrhea causes a potential risk of ascending infection, which mandates surgical repair. Surgical repair is needed in all cases of spontaneous leaks and recurrent leaks, leaks that do not stop after conservative management, and cases with history of meningitis or with a history of CSF rhinorrhea. In our child, since it is a case of spontaneous CSF rhinorrhea with recurrent meningitis, it has to be closed surgically as early as possible. An endoscopic approach has become the initial approach of choice. An endonasal endoscopic approach has a success rate of over $90 \%$ with lower morbidity when compared with intracranial techniques. ${ }^{5}$ Once the defect is identified, the surrounding mucosa should be debrided before the laying of grafting material because sinus mucosa contains mucus producing glands which can lift the graft from the recipient bed. At this point, it will be appropriate to discuss the approach to and general care of such cases of CSF rhinorrhea.
Dr S Balasubramanian:

Obtaining appropriate history of leaks of CSF is essential in diagnosis.

Appropriate consult with neurosurgeon/endoscopic ENT surgeon and radiologist should be obtained in all suspected cases of CSF leaks for planning investigations and treatment.

- Conservative treatment has been advocated in cases of immediate-onset CSF rhinorrhea following head injury since it may spontaneously resolve. A 7-10-day trial of bed rest with the head of the bed elevated approximately 15 to $30^{\circ}$ has been recommended. Avoidance of straining, retching, or nose blowing may result in resolution of the majority of traumatic CSF leaks in a week.

- Prophylactic antibiotics have not been shown to reduce the risk of meningitis and may increase the risk of infection with more virulent organisms.

- Conservative treatment has been associated with a high incidence of meningitis.

- Vaccinations for pneumococcus and meningococcus are important preventive measures which should be taken if children with CSF leaks have not been given these vaccines earlier.

- A systematic approach to diagnosis of the etiology of recurrent meningitis is essential (Flowchart 1).

Dr Dhanalakshmi-ENT surgeon Dr Thirunaukarasu carried out endoscopic surgery for the correction and closure of the defect successfully. The CSF rhinorrhea completely regressed following the surgery, and the boy is on regular follow-up and doing well without symptoms.

\section{References}

1. Tebruegge M, Curtis N. Epidemiology, etiology, pathogenesis, and diagnosis of recurrent bacterial meningitis. Clin Microbiol Rev 2008;21(3):519-537. DOI: 10.1128/CMR.00009-08.

2. Janocha-Litwin J, Simon K. Recurrent meningitis-a review of current literature. Przegl Epidemiol 2013;67(1):41-45.

3. Adriani KS, van de Beek D, Brouwer MC, et al. Communityacquired recurrent bacterial meningitis in adults. Clin Infect Dis 2007;45(5):e46-e51. DOI: 10.1086/520682.

4. Durand ML, Calderwood SB, Weber DJ, et al. Acute bacterial meningitis in adults. A review of 493 episodes. N Engl J Med 1993;328(1):21-28.

5. Ommaya AK, Di Chiro G, Baldwin M, et al. Non-traumatic cerebrospinal fluid rhinorrhoea. J Neurol Neurosurg Psychiatry 1968;31(3):214-225. DOI: 10.1136/jnnp.31.3.214.

6. Russell T, Cummins BH. Cerebrospinal fluid rhinorrhea 34 years after trauma: a case report and review of the literature. Neurosurgery 1984;15(5):705-706.

7. Colquhoun IR. CT cisternography in the investigation of cerebrospinal fluid rhinorrhea. Clin Radiol 1993;47(6):403-408. DOI: 10.1016/S00099260(05)81061-X.

8. Skedros DG, Cass SP, Hirsch BE, et al. Sources of error in use of beta-2 transferrin analysis for diagnosing perilymphatic and cerebral spinal fluid leaks. Otolaryngol Head Neck Surg 1993;109(5):861-864. DOI: $10.1177 / 019459989310900514$.

9. Briggs RJS, Wormald PJ. Endoscopic transnasal intradural repair of anterior skull base cerebrospinal fluid fistulae. J Clin Neurosci 2004;11(6):597-599. DOI: 10.1016/j.jocn.2003.09.011. 